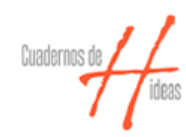

Cuadernos de $\mathrm{H}$ ideas

ISSN: 2313-9048

cuadernosdehideas@perio.unlp.edu.ar

Universidad Nacional de La Plata

Argentina

\title{
Objetividad y discurso en las ontologías de Laclau y Zižek: controversias entre la abundancia y la falta
}

Reartes, Miguel David

Objetividad y discurso en las ontologías de Laclau y Žižek: controversias entre la abundancia y la falta

Cuadernos de $\mathrm{H}$ ideas, vol. 13, núm. 13, e024, 2019

Universidad Nacional de La Plata, Argentina

Esta obra está bajo una Licencia Creative Commons Atribución-NoComercial-Compartirlgual 4.0 Internacional. 
Artículos

\title{
Objetividad y discurso en las ontologías de Laclau y Žižek: controversias entre la abundancia y la falta
}

\author{
Objectivity and discourse in the ontologies of Laclau and \\ Žižek: controversies between Abundance and Lack \\ Miguel David Reartes miguel.reartes@gmail.com \\ Universidad Nacional de La Plata - Becario de la Comisión de \\ Investigaciones Científicas de la Provincia de Buenos Aires, Argentina \\ D http://orcid.org/0000-0003-3227-5263
}

Recibido: 26/07/19

Aceptado: 06/10/19 Publicado: 21/10/19

DOI: https://doi.org/10.24215/23139048e02
Resumen: En este trabajo intentaremos reconstruir la noción de discurso de Ernesto Laclau, buscando con ello dar cuenta del modo en que se configura el registro de la objetividad en de las distintas etapas de su propuesta teórica. Al mismo tiempo, buscaremos establecer un contrapunto entre la perspectiva de Laclau y el abordaje que realiza Slavoj Žižek de esta misma dimensión. Intentaremos inscribir el debate entre ambos autores en el marco de la distinción formulada por Tønder y Thomassen entre las ontologías de la falta y las ontologías de la abundancia, con el objetivo de indagar en torno a algunas de las controversias que atraviesan al proyecto teórico de Laclau en su intento por articular ambas orientaciones.

Palabras clave: Ernesto Laclau, Slavoj Žižek, Discurso, Abundancia , Falta .

Abstract: In this work we will try to reconstruct Ernesto Laclau's notion of discourse, seeking to account of how the objectivity register is configured in the different stages of his theoretical proposal. At the same time, we will seek to establish a counterpoint between Laclau's perspective and Slavoj Žižek's approach of this same dimension. We will try to insert the debate between both authors in the context of the distinction made by Tønder and Thomassen between the ontologies of lack and the ontologies of abundance, with the aim of inquiring around some of the controversies that go through Laclau's theoretical project in its attempt to articulate both orientations.

Keywords: Ernesto Lacau, Slavoj Žižek, Discourse, Abundance, Lack .

\section{Introducción}

Ernesto Laclau ha construido un enfoque teórico original a partir de la articulación de diversas corrientes de pensamiento, entre las que se destacan la analítica existencial de Martin Heidegger, la filosofía posanalítica de Ludwig Wittgenstein, la teoría de la hegemonía de Antonio Gramsci y las distintas vertientes del posestructuralismo, tomando como principales referencias la deconstrucción de Jacques Derrida y el psicoanálisis de Jacques (Laclau, 2011a).Sin embargo, y como el propio autor reconoce, es al interior del campo posestructuralista donde ha encontrado sus influencias más relevantes, considerando la impronta de la deconstrucción desde su obra conjunta con Chantal Mouffe, Hegemonía y estrategia y socialista ([1985] 2004), y en virtud de su progresiva incorporación de las nociones del psicoanálisis lacaniano, 
con especial énfasis a partir de su obra Nuevas reflexiones sobre la revolución de nuestro tiempo ([1990] 2000a). En el marco de una articulación realizada a partir de la búsqueda de lógicas conceptuales comunes entre las distintas corrientes teóricas, Laclau ha elaborado una noción de discurso que se ha constituido en piedra angular para el desarrollo de una ontología sobre lo social, en la medida en que constituye el nombre a partir del cual puede concebirse el campo de la objetividad como tal.

Esta articulación, sin embargo, no ha estado exenta de tensiones y polémicas. Si bien en la obra de Laclau la deconstrucción y el psicoanálisis se han considerado siempre dos corrientes complementarias al interior del posestructuralismo, no existe un claro consenso en torno a esta posición. Es por ello que el autor argentino ha disputado una determinada interpretación de este legado en función de las exigencias de su propia empresa teórica, en discusión con una amplia variedad de autores que han planteado distintas formas de comprender las premisas ontológicas de ambas corrientes. Entre los que han confrontado con el autor argentino cabe destacar al filósofo esloveno Slavoj Žižek, cuya perspectiva teórica inscrita en el psicoanálisis lacaniano -que a su vez ha planteado una reapropiación creativa del idealismo alemán y ha incorporado a algunos preceptos del pensamiento marxista- en gran medida se ha formulado a partir de un diálogo productivo con la obra de Laclau (sobre todo en sus primeras obras), siendo públicamente reconocidas las influencias mutuas entre ambos autores. En este sentido, en el pensamiento de Žižek encontramos una noción de discurso claramente lacaniana, que a diferencia de Laclau rechaza como injustificadas las pretensiones de conciliar en términos teóricos la perspectiva de Lacan con otras vertientes del posestructuralismo, negando la pertenencia del psicoanalista francés a dicho campo. Tenemos aquí un debate que ha signado la evolución teórica de ambos autores, y que ha sido uno de los puntapiés iniciales de muchos de sus desencuentros posteriores.

Consideramos que las distintas orientaciones teóricas que Laclau y Žižek ofrecen a partir de sus divergentes interpretaciones del pensamiento lacaniano y posestructuralista pueden estimarse de manera más precisa en función del privilegio ontológico que cada uno asigna a la falta o a la abundancia en sus respectivos abordajes, determinación que afectará de manera desigual al pensamiento de Laclau en las distintas etapas de formulación de su obra. Aquí nos referimos a una distinción abordada en la obra Radical democracy. Politics between abundance and lack, compilada por Lars Tønder y Lasse Thomassen (2005). Los distintos trabajos de este volumen intentan recomponer un conjunto de debates que atraviesan al posestructuralismo (aunque excediendo sus márgenes) a partir de la oposición entre, por un lado, un pensamiento basado en la postulación de una falta constitutiva no simbolizable que opera en el corazón de todo sujeto o sistema de significación -cuyo exponente fundamental es el enfoque teórico de Jacques Lacan-, y por el otro, un pensamiento cimentado en las formas plurales y creativas de afirmación positiva sobre los cuales se articula toda experiencia, que introducen siempre un exceso de ser que es ontológicamente primario a la falta -en cuya referencia se 
inscriben la mayoría de los autores posestructuralistas, en especial Gilles Deleuze y Jacques Derrida-. Aunque ambas orientaciones confluyan en su aceptación común de la inestabilidad de todo fundamento ontológico, esta distinción cobra relevancia en tanto designa dos formas de comprender y explicar este descentramiento constitutivo, de modo tal que la elección entre una u otra tendrá implicaciones teóricas -y políticasdiferenciadas.

En este sentido, en este artículo nos proponemos abordar algunas tensiones que, desde nuestra perspectiva, atraviesan al pensamiento de Laclau en su intento por combinar una noción de discurso concebida bajo la impronta de una idea de abundancia -resultante de la influencia de distintas variantes del posestructuralismo, sobre todo la deconstruccióncon su cada vez más acentuado intento por introducir la dimensión de la falta lacaniana a esta conceptualización, abordando para ello sus trabajos desde la publicación de Hegemonía y estrategia socialista (primera obra del autor inscrita en el posestructuralismo) en adelante. Sin embargo, en la medida en que el discurso no constituye una categoría regional del pensamiento de Laclau sino la base de una ontología sobre lo social, este análisis necesariamente nos conducirá una perspectiva más general referida al modo en que se configura la objetividad en la teoría de Laclau.

Por otro lado, buscaremos contraponer a esta perspectiva el abordaje de la dimensión discursiva realizado en algunas de las obras más relevantes de Žižek, autor cuyo pensamiento se referencia más firmemente en la ontología de la falta lacaniana. ${ }^{1}$ Este segundo objetivo puede en gran medida formularse en diálogo con el primero, en la medida en que, como veremos, la perspectiva y las críticas formuladas por Žižek tendrán un impacto directo en las revisiones que realizará Laclau en su propio enfoque teórico, y en este sentido cumplirá (junto a otros autores como Stavrakakis, Glynos y Copjec) un papel muy importante en el "giro lacaniano" del autor argentino. De este modo, más que indagar en la naturaleza específica del proyecto teórico žižekiano (cuestión que implicaría un trabajo mucho más extenso), nuestro abordaje del autor esloveno tendrá como fin delimitar un campo teórico de debates compartido con Laclau, reponiendo algunas dimensiones de la falta y la abundancia que consideramos pueden servir para complementar y ampliar los enfoques trabajados en la obra de Tønder y Thomassen.

$\mathrm{Al}$ mismo tiempo, la contraposición entre ambos autores es relevante en la medida en que configuran -junto a Alain Badiou- los principales exponentes de lo que Yannis Stavrakakis (2010) ha llamado la "izquierda lacaniana”, y en este sentido expresan dos orientaciones diferenciadas de la apropiación del pensamiento lacaniano desde la teoría política. Reponer el contrapunto teórico entre las dos propuestas nos permitirá así analizar el modo en que cada uno de ellos interpreta y problematiza un conjunto de influencias teóricas compartidas. Y esto, a su vez, será determinante para comprender las conclusiones a las que cada uno de ellos arribará, que darán lugar a importantes divergencias en el devenir de su debate. Sin embargo, nuestra hipótesis principal será que las tensiones inicialmente planteadas por esta articulación en la obra de Laclau se 
saldarán en gran medida a partir de la cada vez más clara subordinación de la abundancia por una falta ontológicamente prioritaria, planteando así un acercamiento al pensamiento de Žižek que a veces se suele soslayar. ${ }^{2}$

\section{Falta y abundancia: una distinción ontológica}

En este apartado intentaremos reconstruir sintéticamente los contornos de la distinción entre las "ontologías de la falta" y las "ontologías de la abundancia”, así como algunas de las características más importantes de estas dos orientaciones teóricas. La misma aparece formulada en la introducción a Radical democracy..., escrita por Tønder y Thomassen (2005), y es recuperada por los distintos autores que participan en la elaboración de esta obra. Si bien la conceptualización de estas dos ontologías se orienta especialmente hacia la discusión en torno al proyecto intelectual y político que los autores defienden -la "democracia radical", proyecto inicialmente formulado por Laclau y Mouffe en Hegemonía y estrategia socialista- a lo largo de este trabajo buscaremos recuperar la dimensión teórica de esta distinción. ${ }^{3}$

Por su parte, Marchart (2005) traza una genealogía que busca rastrear los orígenes teóricos de la conceptualización lacaniana de la falta, que remiten a los aportes de Heidegger, Kojève y Sartre. Esta refiere en sus comienzos a la noción de finitud heideggeriana -el Dasein como serpara-la-muerte-, reinterpretada a la luz de la dialéctica kojèviana como negatividad, comprendiendo la historia en función de un antagonismo fundamental constituido por el deseo de reconocimiento del otro -el deseo de un deseo si contenido positivo: es decir, una nada-. A estos aportes se suma el trabajo de Sartre, que introduce una noción de sujeto como falta, ausencia que sin embargo posibilita desvincular el reino humano del ser causal y determinado. Estos elementos serán abordados por Lacan, combinados con la influencia de la lingüística estructural y el psicoanálisis freudiano. En este sentido, Lacan retomará las nociones de finitud y negatividad en su aseveración según la cual el orden del ser se estructurará en términos simbólicos en torno a una falta constitutiva. Comprenderá al mismo tiempo esa falta como una ausencia que habita en el propio sujeto, recuperando así la noción sartreana del sujeto como falta-de-ser. Y esta falta en el sujeto será, justamente, aquello que pone en movimiento a la dialéctica del deseo de Kojève. Asimismo, radicalizará dicha noción de deseo como presencia de una ausencia, refiriéndose al deseo como deseo del Otro, cuya finalidad es recubrir esta ausencia constitutiva al orden simbólico. Abordaremos algunos de estos elementos con más profundidad a lo largo del trabajo; destacaremos sin embargo que la influencia de las ontologías de la falta será determinante para el trabajo de autores como Laclau, Žižek y Badiou.

La otra orientación que Tønder y Thomassen identifican es la de las "ontologías imaginarias de la abundancia", cuyo exponente principal es Gilles Deleuze. Tal como indican los autores, el argumento de Deleuze es que los lacanianos permanecen atrapados por el espectro del estructuralismo, «que no aprecia la complejidad y profundidad de la vida 
social, pero en cambio reduce la experiencia de la diferencia a una cuestión de fracaso» (Tønder y Thomassen, 2005, p. 6) . ${ }^{4}$ Deleuze, como uno de los filósofos posestructuralistas de la diferencia, ${ }^{5}$ plantea que la diferencia opera al interior de un conjunto de redes constituidas de manera contingente, que son capaces de sintetizar la multiplicidad diferencial y producir algo radicalmente nuevo y distinto, sin que medie en este proceso la necesidad de llenar una falta pre-existente. La idea del "rizoma" remite a esta necesidad de comprender los procesos de producción social y simbólica a partir de un fenómeno de superabundancia del ser, que se expresa en procesos de afirmación positiva a partir de redes y flujos de pluralidad material irreductibles a un principio único. Marchart (2005) agrega que si bien Deleuze afirma la primacía del deseo (al igual que Lacan), en su obra éste no aparece prescripto por una primordial falta-de-ser, sino que esta falta es meramente secundaria: «la falta refiere a la positividad del deseo, y no el deseo a una positividad de falta. Aquí, el fenómeno de la positividad o superabundancia de ser es ontológicamente primario al fenómeno de la falta y la negatividad» (p. 26, destacado en original). ${ }^{6}$

Además de Deleuze, destacan en esta corriente varios de los filósofos franceses del posestructuralismo cuya producción teórica comienza hacia fines de los años sesenta, tales como Felix Guattari (colaborador de Deleuze en muchos de sus más importantes trabajos), Michel Foucault y Jacques Derrida ${ }^{7}$ Por otra parte, si bien en la obra de Tønder y Thomassen no se formula una genealogía de las ontologías de la abundancia a la par de la que realiza Marchart con las ontologías de la falta, podemos afirmar ${ }^{8}$ que éstas se originan en gran medida a partir de su rechazo común a las influencias que dominaron a la generación precedente de filósofos franceses (Hyppolite, Kojève, Sartre y MerleauPonty), signada en términos intelectuales por las "tres Hs": Hegel, Husserl y Heidegger . Se destaca, en este sentido, el ascendiente dejado por los autores que Ricœur denominó "los maestros de la sospecha": Nietzsche, Marx y Freud. En especial, la influencia de Nietzsche será determinante para autores como Foucault, Deleuze, Guattari y -en menor medidaDerrida, cuyas conceptualizaciones de la abundancia pueden analizarse bajo la impronta de la afirmación nietzcheana, comprendida a partir de una indeterminación genética radical y el azar absoluto del devenir, cuyo curso es irreductible a una falta de origen (Derrida, 1989).

Huelga también decir que los distintos autores que elaboran la distinción entre falta y abundancia son los primeros en intentar deconstruirla. Tønder y Thomassen (2005) señalan que cada una de estas orientaciones no constituye el simple reverso de la otra, ya que en un gran número de discusiones existen posturas cruzadas entre los distintos referentes de cada corriente. ${ }^{10}$ A pesar de sus diferencias, la mayoría de los aportes de esta obra han intentado, a la vez que teorizan esta distinción, matizar y en cierta medida diluir sus límites, ${ }^{11}$ planteando una complementariedad de base que remite al hecho de que ambas orientaciones comparten la postulación de "fundamentos ontológicos inestables”, como los ha llamado Marchart (2005). ${ }^{12}$ En este sentido, 
tanto los teóricos de la falta como los teóricos de la abundancia tienen como punto de partida la tesis lefortiana sobre el fin de los marcadores de certeza que constituían la base del pensamiento moderno, aceptando por ende la incompletitud estructural y la ausencia de plenitud como condición positiva de toda objetividad (Norval, 2005).

A pesar de estas coincidencias, creemos necesario recuperar la especificidad de la distinción en el nivel teórico, dando cuenta del modo en que la elección por una u otra ontología conlleva efectos variables en cada enfoque, cuya compatibilización deviene a veces una empresa muy difícil. Para ello buscaremos a continuación rastrear sus huellas en la noción de discurso de Ernesto Laclau, la cual constituye una de las más ambiciosas apuestas contemporáneas por combinar enfoques de distintas tradiciones teóricas, para luego compararlo con la perspectiva de Slavoj Žižek, cuya obra inscrita en el paradigma lacaniano de la falta rechaza por principio esta forma de articulación teórica.

\section{Laclau: el discurso como abundancia}

Para Laclau, desde la publicación de Hegemonia y estrategia socialista (Laclau y Mouffe, 2004), el discurso es el terreno primario de constitución de la realidad como tal, en tanto no es posible acceder a la realidad como tal de manera inmediata: ésta siempre se halla mediada, atravesada por una determinada inscripción simbólica. El sentido se construye a partir una inscripción significante que acontece siempre al interior de una determinada formación discursiva, de modo tal que la realidad es siempre representativa. En este sentido, en la medida en que todo objeto solo puede ser pensado bajo coordenadas discursivas, no existe ninguna posibilidad de acceder a la realidad perse, en su naturaleza esencial: nuestra existencia es siempre simbólica, y esta dimensión discursiva constituye el horizonte último de lo que se comprende como realidad.

Esto desde ya marca una distancia con una de las principales trayectorias de las "ontologías de la abundancia": la deleuziana. ${ }^{13}$ Siguiendo los escritos de Spinoza sobre la unicidad de la naturaleza, para Deleuze no existe nada por fuera del campo del ser (Thonder y Thomassen, 2005). En este sentido, como ha señalado Žižek (2016), Deleuze se distancia fuertemente del diferencialismo de cuño estructuralista -la afirmación de una estructuralidad signada por una carencia central que garantiza la consistencia de sus elementos en términos negativos- en aras de una positividad absoluta, que no depende de ningún marco formal impuesto "desde afuera", y cuyas reglas de surgimiento y funcionamiento son absolutamente inmanentes: no plantean ninguna brecha entre el espacio vacío de la estructura y el elemento que ocupa dicho lugar. La significación es, en este sentido, meramente secundaria respecto a la inmanencia. Y esto también puede aplicarse al pensamiento de otros autores posestructuralistas: por ejemplo, Foucault, cuyo concepto de "episteme" tampoco constituye un sistema diferencial formal, «sino una colección de singularidades contingentes, de las reglas de su surgimiento y desaparición» (Žižek, 2016, p. 183). 
La visión de Laclau, desde una primera aproximación, se manifiesta más cercana al estructuralismo. Si el terreno del ser solo existe en la medida en que es representado a partir de una articulación discursiva, esto implica la implica asumir una imposibilidad de acceder a la inmanencia del ser en su sustancialidad. Para Laclau todo elemento no puede analizarse sino es en su estructuralidad, su relación diferencial negativa al interior de una determinada estructura discursiva. Sin embargo, la crítica de Laclau al estructuralismo lo acerca en gran medida en algunas formulaciones de Deleuze, en la medida en que para el autor argentino las estructuras nunca llegan a constituir un sistema; es decir, un objeto identificable e inteligible -en otras palabras, una esencia (Laclau, 2000b). Por el contrario, Laclau considera necesario conceptualizar los procesos que impiden comprender a la objetividad como presencia fija y plena. Esta necesidad no lo conduce a seguir el camino spinoziano y a desechar toda estructuralidad, sino que su desafío es comprender las lógicas a partir de las cuales el discurso como terreno ontológico primario constituye una dimensión siempre abierta e indeterminada.

El autor más importante para comprender este descentramiento estructural constitutivo en Hegemonía y estrategia socialista y los trabajos posteriores del autor argentino, es Jacques Derrida y su método deconstructivo.$^{14}$ Para Derrida (2017) la realidad carece de un centro que detenga y funde el significado, de modo tal que ésta solo existe en los múltiples intentos por significarla desde el lenguaje, a partir del libre juego de la escritura. La ausencia de este centro debe leerse como un no-lugar, un espacio vacío que da a lugar a una sustitución infinita de signos en la búsqueda de clausura de un conjunto finito -el lenguaje-. Derrida llama suplemento al significante flotante que cumple la función vicaria de suplir esta ausencia de significado. El juego de la différance derrideano es un juego que simultáneamente involucra un momento de ausencia y (un excedente de) presencia: el vacío de la presencia original ausente, y su suplemento discursivo, que se actualiza infinitamente en la búsqueda por ocupar dicha ausencia. Sin embargo, la suplementación no se limita a llenar una falta pre-existente, sino que siempre «añade algo, es lo que hace que haya siempre más» (Derrida, 1989, p. 397, destacado en original); es decir, impulsa siempre nuevas diferencias a ser. $\mathrm{Al}$ mismo tiempo, toda nueva sustitución se constituye en torno a cadenas discursivas cuyo significado siempre es contextual y determinado, siendo imposible encontrar un sentido "último" y literal a las cosas. La significación deviene así un juego eterno, un texto literario abierto en el cual todo intento por aprehender el significado nos lleva de un signo hacia el otro, y así a un proceso de diseminación ad infinitum, en tanto no es posible hallar un límite trascendental que garantice la consistencia ontológica del conjunto.

La noción de discurso formulada por Laclau y Mouffe en Hegemonía y estrategia socialista (2004) puede comprenderse a partir de estos desarrollos de Derrida. Como ya hemos señalado, en la medida en que no existe una naturaleza primera a la que la representación refiera, el discurso es el terreno primario de constitución de toda objetividad. En este sentido, los autores postulan que toda identidad logra alcanzar algún 
grado de fijación en el terreno del discurso a través de la institución de "puntos nodales" ${ }^{15}$ como aquellos "puntos discursivos privilegiados" que fijan el sentido a la cadena significante (como puede ser "Dios" en un discurso religioso o la palabra "nación" en un discurso nacionalista). Sin embargo, siguiendo los planteos de Derrida, en tanto lo social es concebido como "campo de discursividad", carece de un centro que detenga el juego de la significación, de modo tal que toda identidad mantiene un carácter abierto y sus elementos poseen una naturaleza "flotante". En otras palabras, la no-fijación definitiva de los elementos producto de la inexistencia de un principio ordenador que les otorgue un significado unívoco o esencial, implica asumir la naturaleza contingente de sus inscripciones en torno a determinadas cadenas significantes, lo cual los vuelve factibles de ser rearticulados a múltiple formaciones discursivas. En virtud de ello, toda estructura discursiva aparece esencialmente descentrada, subvertida y desbordada por un exceso significante que es incapaz de controlar, tensionada por la infinidad del campo de la discursividad. De este modo el juego de las diferencias de Laclau repone el juego de la différance derrideano, que involucra al mismo tiempo la aceptación de una ausencia original -un centro que detenga el juego mismo- y un exceso discursivo que desborda continuamente el campo de discursividad, ya que cada nueva sustitución en la cadena de signos instituida incorpora algo distinto que es irreductible a las formas estructuradas del discurso.

Asimismo, en esta obra conviven dos definiciones de discurso o estructura discursiva. En un caso, el discurso es «una práctica articulatoria que constituye y organiza las relaciones sociales» (p. 133); mientras que en el otro constituye la «totalidad estructurada resultante de la práctica articulatoria» (p. 143). Estas definiciones no son contradictorias: el discurso es al mismo tiempo una práctica articulatoria y la estructura que emerge a partir de ella. Uno de los autores claves para comprender esta dualidad es Wittgenstein, ${ }^{16}$ en la medida en que la noción de "estructura discursiva" puede comprenderse en analogía con los "juegos de lenguaje" del autor vienés: como una articulación siempre parcial y situada cuyas reglas de funcionamiento aparecen determinadas por su gramática específica, y no definidas a partir de un criterio a priori. En otras palabras, la estructuralidad nunca opera como un marco impuesto "desde afuera", sino que se constituye en virtud de los propios elementos articulados. En este sentido, si bien toda objetividad se manifiesta de manera estructurada, las reglas de formación de estas estructuras son inmanentes a ellas mismas, en tanto la instancia de aplicación es la propia regla (Laclau, 2011b). De este modo, el discurso como juego -como práctica articulatoria- es correlativo al discurso como momento instituido -como estructura-.

Si nos detuviéramos aquí deberíamos concluir que el pensamiento de Laclau se adecúa sin problemas a la tradición de las "ontologías de la abundancia”. En este sentido, podríamos inscribir la ontología laclauiana en la tradición que es posible pensar a partir del rizoma deleuziano -amén de que en el caso de Laclau, la inmanencia no refiera a una "presencia sustancial" sino a una "presencia discursiva"- y el suplemento derrideano, 
que comprende la realidad a partir de la tesis del exceso inmanente de la presencia por la presencia. Pero la apuesta del autor no se quedará allí, y a través de nociones como antagonismo y hegemonía tensionará estos mismos principios.

\section{Abundancia vs falta: la intervención de Žižek}

En Hegemonia y estrategia socialista, Laclau y Mouffe introducirán la noción de hegemonía. Retomada de Antonio Gramsci, los autores conceptualizan la hegemonía como una lógica de lo político a partir del cual es posible representar el campo de las diferencias en un nivel totalizador. ${ }^{17}$ Sin embargo, pensar el campo de la discursividad como totalidad implica pensar un límite al que las diferencias refieran. Y si,como ha señalado Derrida, este límite no puede ser representado por un elemento positivo (en tanto este elemento debería referirse a una unidad mayor y por ende no sería realmente un límite), entonces éste debe ser leído como una interrupción, una imposibilidad de las diferencias por constituirse plenamente, lo cual desde la mirada de Laclauy Mouffe permitiría pensar una fijación parcial de la diseminación. Esto es posible a través de la articulación discursiva de un antagonismo: es decir, a través de la institución de un "otro" exterior al campo de las diferencias simbólicas que se constituye como negación de la identidad de las mismas, y que en función de esta negatividad común posibilita su unificación como formación discursiva, estableciendo una equivalencia entre los elementos que subvierte su carácter diferencial. La totalización de lo social, de este modo, se configura a partir de un límite negativo que expresa un imposibilidad del orden discursivo por constituirse de manera plena; pero que, gracias a ello, le permite alcanzar alguna clase de objetividad. Por eso mismo, para estos autores, el antagonismo constituye el límite de la objetividad. $^{18}$

Nociones como hegemonía y antagonismo implican una preocupación por ir más allá de los efectos deconstructivos del discurso, buscando crecientemente conceptualizar las formas parciales de "sutura" o cierre a partir de las cuales la realidad en su existencia simbólica puede enmarcarse y adquirir de este modo cierta consistencia objetiva. Esto denota cierta orientación teórica que marca una incipiente distancia respecto a los teóricos de la abundancia, en tanto para los autores de esta tradición no es posible pensar la realidad a partir del establecimiento de una frontera o límite que garantice la consistencia de la objetividad en su dimensión global. Para la deconstrucción, en particular, todo significado aparece diseminado en una cadena infinita de signos, y de este modo todo límite u operación de enmarcado es en última instancia ficticia y arbitraria. Asimismo comprender la realidad como un texto abierto implica que el discurso nunca se limita a representar o reproducir el orden dado: ya que toda nueva sustitución es ya su propia lectura e interpretación, ésta siempre introduce un elemento excedente, de modo tal que incorpora una distancia respecto a las formas instituidas del discurso. Esto conlleva la 
imposibilidad de un único relato que pueda erigirse como amo del texto, imponerse como "verdad".

La postura de $\check{Z Z i z ̌ e k}^{19}$ nos permite incorporar otros elementos al enfoque lacaniano de la falta, que anuncian notablesdivergenciasrespecto del camino señalado por las ontologías de la abundancia. Si, como hemos señalado, la suplementación plantea una discontinuidad en el orden del ser en la medida en que el texto es ya su propia interpretación y en este sentido agrega algo: un excedente que configura un significado nuevo, el problema para Žižek reside en que lo que el discurso dice -la interpretación- es siempre distinto a lo que el discurso quiere decir (en tanto introduce un sentido nuevo). Pero si seguimos la lectura de Žižek, para Lacan existe un momento en el que el discurso dice lo que quiere decir o, en otras palabras, se constituye como referencia objetiva. Aquí se confrontan distintas visiones del discurso como verdad, que remiten a disímiles modos de comprender la función del significante, aquello que éste encarna y representa. Si para la orientación deconstructiva toda verdad es una ilusión provocada por efecto de determinados mecanismos textuales, Lacan por el contrario reivindica el psicoanálisis como "experiencia de verdad". Ahora bien, esta verdad no se alcanza a partir de un retorno al arché, a una presencia originaria esencial, sino por el contrario, se constituye encarnando la imposibilidad del significante como tal, representando el fracaso del sistema simbólico por constituirse de manera plena. En otras palabras, a partir de la materialización imposible de lo Real, comprendido como el registro que aquello que es irrepresentable en términos simbólicos. Si para Lacan «toda verdad tiene estructura de ficción » es porque solo confrontando con su propio fracaso que la realidad puede alcanzar una cierta existencia objetiva.

Podemos reseñar este proceso remitiéndonos a las figuras retóricas de la metonimia y la metáfora, que remiten en términos lingüísticos a las operaciones de combinación y sustitución (y en el psicoanálisis freudiano, a las operaciones de desplazamiento y condensación). Para la deconstrucción existe un predominio de la metonimia por sobre la metáfora, en la medida en que el significado aparece diseminado en cadenas de signos a través de relaciones de contigüidad. En cambio en la propuesta lacaniana -tal cual la reconstruye Žižek-, la metonimia siempre se apoya en un corte metafórico, un anclaje objetivo en torno al cual la cadena de signos se articula. El objeto metaforizado no es sin embargo una presencia positiva, un registro primario a develar que antecede al propio lenguaje, sino lo Real en tanto imposibilidad inherente al lenguaje mismo. Es a través de la objetivación metafórica de un vacío, de una brecha intrínseca al orden simbólico, que éste adquiere consistencia. Esta es la función del point de capiton (punto de almohadillo, retomado por Laclau como "punto nodal"), el significante que, a través de una operación de "acolchado" (capitonnage) produce la ilusión del significado.

Como ha señalado Žižek (2012), el debate entre el discurso como texto abierto y diseminado, y el discurso como objetividad (fallida) constituye uno de los puntos centrales del desencuentro entre la teoría lacaniana y otras vertientes del posestructuralismo. Si bien, como hemos 
visto, los teóricos que hemos referenciado con las ontologías de la abundancia asumen que toda identidad se constituye a partir de una falta o ausencia fundamental, ésta remite fundamentalmente a la comprensión de que todo fundamento ontológico es esencialmente contingente; que la contingencia es, paradójicamente, necesaria -y es justamente aquello que permite la infinitud del juego como tal-. Sin embargo, el reproche realizado por estos autores a Lacan refiere a la pretensión de su teoría por encarnar la falta como tal, la posibilidad formulada de circunscribir o mapear la imposibilidad al interior del orden simbólico, significando a través de un gesto negativo al orden en función de su propio límite. Para ellos, localizar la falta en un lugar de excepción que garantice la consistencia del conjunto es visto como un intento de retorno al Uno, a la metafísica de la presencia. La diseminación textual no puede ser dominada.

Sin embargo, según Žižek, la infinita diseminación textual es justamente lo que aparece en discusión en el pensamiento lacaniano. Amparada en la fórmula según la cual "todo es lenguaje”, el fundamento de esta diseminación constituye, paradójicamente, una forma de metalenguaje: la interpretación del texto. Para Lacan, en cambio, todo es lenguaje porque todo objeto aparece ya constituido como objeto-lenguaje. Hay una referencia significante que es, en este preciso sentido, objetiva. Referencia que, por supuesto, no está dada por la sustancialidad del objeto sino por el significante en tanto positivización de un vacío. De este modo, el juego de la significación no puede pensarse en los términos de una "abundancia" que introduzca un pliegue en el orden del ser, en tanto las diversas sustituciones tienen como punto de partida determinado un terreno común de signos constituidos objetivamente; es decir: no añaden nada nuevo, sino que constituyen desplazamientos al interior de una matriz ya instituida. $\mathrm{Y}$ es por ello que el orden del signo, entendido por Lacan como el registro de lo Simbólico, no es un orden de apertura y libertad ilimitadas, sino un orden que impone principios de estructuración, a partir del cual se constituye toda identidad en función de mecanismos de identificación.

Sin embargo, lo que diferencia a Lacan de los autores del estructuralismo es que para el primero existe siempre un punto en el cual la interpelación simbólica fracasa, tropieza con su propia imposibilidad de encarnar el significado en tanto Real. En este sentido, lo social nunca puede borrar su propia imposibilidad traumática, la cual se manifiesta a través de sus propios fallos e interrupciones, que distorsionan permanentemente los procesos de identificación. Este fracaso estructural es, justamente, el lugar del sujeto en su dimensión auténtica: el punto ciego de la significación en torno al cual es posible pensar su subversión radical, el repliegue del orden instituido y su rearticulación en torno a nuevos principios -un nuevo significante Amo-. De este modo, el momento de libertad e indeterminación del orden es el momento de irrupción del sujeto, no en su dimensión simbólica -las foucaultianas "posiciones de sujeto" que Laclau retomará- sino como el sitio donde acontece el fracaso de la interpelación. 
En este sentido, cuando Norval (2005) bien estipula los diferentes puntos de partida analíticos que suponen las ontologías de la abundancia -cuya comprensión parte de un mapeo alternativo y genealógico de un determinado terreno que busca revelar sus múltiples posibilidades constitutivas- respecto al que postulan las ontologías de la falta -cuya atención se dirige a los modos de intervención del sujeto y el fracaso o éxito de su identificación-, esta diferencia no puede concebirse únicamente como una mera elección de sesgos que cada propuesta teórica elige tematizar. El foco en la dimensión del sujeto en la ontología lacaniana -el lugar de la falta- cobra sentido en relación a una concepción de la objetividad que, como hemos visto, suprime la posibilidad de pensar la significación como presencia excedente (suplementaria o rizomática). Y a la inversa, centrar nuestra atención en la construcción de sentido partiendo únicamente de los desplazamientos constitutivos del discurso, conlleva pensar la objetividad solo en su dimensión de apertura radical, y no en función de su propia finitud e imposibilidad estructurante. Vemos así el modo en que dos nociones de discurso afirmadas en distintas ontologías conllevan conclusiones opuestas en sus respectivos terrenos, de modo tal que, en este punto, falta y abundancia se invalidan mutuamente.

La reconstrucción de este debate nos posibilita analizar aquello que se pone en juego en el intento de Laclau por conciliar una noción de discurso de ribetes deconstruccionistas con su temprano intento por domar el terreno de las identidades a partir del establecimiento de un límite de lo social. A través de la noción de hegemonía introducida en Hegemonía y estrategia socialista, Laclau hace algo más que plantear una fijación parcial de las estructuras discursivas: éstas sobrevienen elementos interiores e inherentes a un determinado ordenamiento discursivo. De este modo, existe un momento en que la realidad se constituye como referencia objetiva totalizante, un momento en el que, en los términos reseñados, el discurso refleja realmente lo que quiere decir en tanto objetivación de una verdad. Esto, consideramos, pone severamente en cuestión su noción más radical de estructura discursiva formulada en esa misma obra, entendida como una práctica articulatoria que produce un exceso de sentido, y cuyas reglas de formación y funcionamiento son inmanentes a los propios elementos articulados (y no a un principio exterior totalizador). No es sencillo compatibilizar una noción de discurso que remita a los desplazamientos que acontecen al interior de una referencia objetiva ya constituida, con una noción de discurso que redefina continuamente los confines ontológicos de la realidad. En este sentido, o bien el límite totalizador es absolutamente circunstancial y ficticio -y es continuamente subvertido por su excedente discursivo-, o abandonamos esta idea de abundancia y comprendemos las diversas instituciones discursivas en un sentido lacaniano, como identificaciones al interior de un sistema de signos constituido objetivamente. Mientras que en la obra señalada Laclau y Mouffe no definen un único camino, consideramos que en sus obras subsiguientes el autor argentino se posicionará decisivamente en la segunda senda. 


\section{La irrupción de lo Real: el repliegue de la abundancia}

Žižek fue uno de los autores que más tempranamente anticipó una orientación lacaniana en las reflexiones de Laclau -y en cierta medida, colaboró hacia ella-. En este sentido, el autor esloveno postuló que la noción de antagonismo del autor argentino constituye una manifestación de la irrupción de lo Real en lo Simbólico, la objetivación de una brecha de imposibilidad a partir de la cual la estructuración de la realidad deviene posible. ${ }^{20}$ Žižek, sin embargo, cuestionó la igualación del momento de la falta respecto a su externalización en torno a otro-antagónico: no es el enemigo quien me impide alcanzar la identidad plena, sino que ésta aparece ya marcada, atravesada por un núcleo traumático de imposibilidad, y este punto de fracaso de la subjetivación es el nombre mismo del sujeto. Estas apreciaciones serán aceptadas en buen grado por Laclau en sus obras sucesivas, abriendo el paso a una conceptualización cada vez más sistemática de las nociones lacanianas, relegando a un segundo plano su anterior idea de abundancia y explorando a fondo las consecuencias de la falta.

Señalaremos algunos de los cambios más importantes en esta transición. En Nuevas reflexiones sobre la revolución de nuestro tiempo (2000) Laclau introduce una noción de falta a partir de su concepto de dislocación, entendido como el momento de indecidibilidad radical de las estructuras, la emergencia de una instancia de libertad, posibilidad y temporalidad absolutas a partir de la cual es posible pensar una reconstitución radical de lo social. La dislocación remite a un descentramiento constitutivo de la realidad, al hecho de que la significación nunca puede fijar un significado pleno, y por ende sobre sus fallas e intersticios emerge la posibilidad -dentro de determinado horizonte histórico- de una apertura del orden en su dimensión más radical. La noción de dislocación es ontológicamente primaria al antagonismo (que expresa ahora la inscripción de la dislocación en términos discursivos), y constituye la aceptación de una finitud o falta que habita en el corazón del orden simbólico. Remite de este modo al "límite de la objetividad", y por eso será conceptualizada por el propio Laclau como el momento de irrupción de lo Real, la manifestación de una imposibilidad radical en el orden del discurso.

Esta noción de dislocación irá de la mano de una nueva concepción sobre el sujeto, entendido como la «distancia entre la estructura indecidible y la decisión» (Laclau, 2000, p. 47, destacado en original), lo que conlleva pensarlo en la línea lacaniana de Žižek: como un punto ciego en las estructuras, su lugar vacío (y en este sentido, aquello que posibilita su apertura). Sujeto que asimismo puede devenir en subjetivación o posición de sujeto a partir de su identificación con las posiciones estructuradas del discurso, pero que en sí mismo constituye el momentode su interrupción radical. Como indicará posteriormente el propio Laclau (2008), a partir del momento de irrupción del sujeto como falta es posible pasar de la dislocación como condición ontológica a la dislocación como "acontecimiento histórico", haciendo coincidir 
las dos faltas -en el sujeto y en el Otro simbólico- en el momento lacaniano de "atravesar el fantasma": es decir, interpelando al lugar vacío de la comunidad y apuntando a su reconstitución radical, a través de la institución de una nueva hegemonía. Esta distinción entre dos nociones distintas de dislocación -una como descentramiento constitutivo y otra como históricamente situada, siendo la primera la condición apriorística de la segunda- permite comprender por qué el orden del discurso solo bajo determinadas coordenadas históricas produce un desplazamiento real en sus términos articulados (como puede ser, por ejemplo, una crisis profunda en el modelo de acumulación, aquello que Gramsci entendería como "crisis orgánica”).

Como corolario de estos cambios, Laclau introduce una nueva distinción entre lo social y lopolítico, siendo el primero el orden de las formas estructuradas y sedimentadas del discurso, y el segundo el momento de reactivación de la contingencia de lo social, el momento en el cual el horizonte simbólico se repliega y puede articularse en torno a nuevos principios. Existe así en Nuevas reflexiones... un cambio en la conceptualización del discurso, que deja de concebirse en los términos de un excedente superabundante, para pasar a comprenderse como un orden objetivamente estructurado que solo bajo determinadas condiciones históricas emerge en su finitud radical, y permite así su reconstitución en torno a lo político.

En su obra Emancipación y diferencia (1996) Laclau continúa incorporando elementos a su orientación lacaniana. A partir del concepto allí introducido de "significante vacío" el autor buscará pasar de lo Real como límite del discurso (presupuesto en la noción de dislocación) a lo Real como estructuración simbólica de dicha imposibilidad, a través de la significación de un punto de excepción simbólico en torno al cual se articula lo social en su universalidad (imposible). En este sentido, la significación de la totalidad social conlleva mapear la falta la universalidad como lugar vacío- al interior de una diferencia intrasocial, que de este modo pasa a constituir por un período histórico el fundamento (negativo) de la plenitud ausente de lo social. Aquí la impronta de Lacan es evidente, en tanto el significante vacío remite al significante Amo, el significante de la castración simbólica. La falta emerge así a través del proceso (fallido) derepresentación de aquello que es irrepresentable al interior del orden simbólico: el orden como positividad plena y cerrada. Y sin embargo, es esta fallida operación lo que posibilita la objetivación del conjunto de las diferencias discursivas.

Sin embargo, es a partir de su clásica obra La razón populista (2005) que Laclau pasa a abrazar decididamente el pensamiento de la falta. Aquí introduce tres nuevos aportes sustanciales a este enfoque. En primer lugar, un nuevo abordaje de su noción de "punto nodal" que lo vuelveequivalente asu noción de significante vacío, ${ }^{21}$ gracias a otra incorporación clave del pensamiento de Žižek: su conceptualización del point de capiton lacaniano. Éste constituye el significante que, como palabra, unifica un determinado campo, constituye su identidad. Significante que, sin embargo, carece de consistencia positiva propia: en sí 
mismo no es más que la «objetivación de un vacío, de una discontinuidad abierta en la realidad por la emergencia del significante» (p. 134). De este modo, es la imposibilidad de representar el significado como Real lo que le da al significante su función de designador puro, vacío. Así, el punto nodal ya no constituye el significante que meramente "fija" el carácter flotante de los elementos discursivos, sino que se postula una manifiesta intención de comprender la significación a partir de la encarnación de un vacío o imposibilidad, que es lo que produce la ilusión del significado como metáfora del mismo.

El segundo aporte clave de La razón populista es la incorporación más sistemática de la dimensión afectiva del psicoanálisis, que remite a las lecturas de Joan Copjec sobre Freud y Lacan. Laclau, en este sentido, retoma la reconstrucción que realiza Copjec de la pulsión de muerte freudiana, que remite a un estado de inanimación o inercia que se constituye como ilusión retrospectiva. Ésta se asocia en el psicoanálisis a la díada primordial madre-hijo, un estado mítico de armonía y plenitud que se considera perdido, y esta pérdida es vivida como una ausencia radical, lo cual conduce al sujeto a buscar recobrar este estado. Alcanzar este objetivo (imposible, en tanto constituye una ilusión) llevaría a la autodestrucción; sin embargo la pulsión en el orden simbólico aparece inhibida, y se desplaza a objetos parciales que constituyen los objetivos de toda pulsión. Estos son los "objetos a" (objet petit a), y constituyen para Lacan el señuelo en torno al cual se articula la fantasía, una encarnación parcial de un goce mítico e imaginario a partir de los cuales se articula el deseo del sujeto (Žižek, 2012). La noción lacaniana del goce (jouis-sence) como algo a la vez prohibido (por la castración simbólica) e imposible (por su naturaleza imaginaria) aparece entonces conceptualizada a través de la investidura catéctica sobre el objeto a. Como indica Laclau (2005), estos objetos parciales no constituyen una «parte de un todo, sino una parte que es el todo» (p. 146, destacado en original); es decir, ocupan el lugar de lo que Freud llama la Cosa imposible (das Ding), y así devienen en el principio estructurante de toda la escena. Llegado aquí, Laclau concluye que la lógica del objeto a es la misma que la lógica hegemónica: la representación de la plenitud de la comunidad a partir de una particularidad que es inconmensurable con ella. ${ }^{22}$

El tercer aporte que el autor incluye en dicha obra es su noción de "heterogeneidad" como opuesta a la "homogeneidad". Mientras que la homogeneidad remite a la relación establecida entre distintas posiciones situadas al interior de un campo discursivo, la heterogeneidad refiere a aquello que carece de ubicación diferencial adentro de un sistema. Constituye, como ha señalado Thomassen (2005), una "exclusión radical" al interior del espacio simbólico, en tanto es aquello que no puede representarse de manera adecuada al interior de la cadena de signos instituida. Por eso, según Laclau, lo heterogéneo se erige como un "Real" de la formación discursiva, la manifestación de aquello que no es simbolizable al interior del orden. Sin embargo, lo heterogéneo irrumpe simbólicamente a través de la emergencia de la demanda: la positivización de la falta, que interpela al sistema en su plenitud ausente y revela así 
la imposibilidad sobre la cual se cimienta. En tanto simbolización de lo heterogéneo y, en este sentido, manifestación de lo Real, la demanda constituye una configuración comparable al sintoma lacaniano: una formación que emerge de las fallas de la significación como represión constitutiva del orden simbólico, que como tal constituye una amenaza y es al mismo tiempo su condición de posibilidad. Lo social como campo discursivo de diferencias pasa a comprenderse así como un espacio fracturado y jaqueado por su propio fracaso, que irrumpe sobre sus límites a través de la presencia de -usando una expresión de Žižek- un remanente "muerto no muerto", recordatorio de la fallida promesa de plenitud del orden.

El argumento de Thomassen merece sin embargo una consideración, respecto al papel que juega la heterogeneidad en el debate entre la falta y la abundancia. Para Thomassen (2005) la heterogeneidad constituye una concepto que media entre las dos ontologías expuestas, en tanto refiere simultáneamente a una falta -la división que introduce el significante vacío entre su positividad óntica y su función ontológica de encarnar lo universal- y una abundancia -el reverso fallido de esta significación: la heterogeneidad como "exceso discursivo" de la comunidad-. No obstante, como el autor bien señala, lo heterogéneo no es algo que simplemente se excluye de la comunidad, sino más bien un límite interno que vuelve indecidible las fronteras entre lo interior y lo exterior. Si concebimos que esta "exclusión radical" se configura como un excedente en relación al orden podríamos sostener este punto. Sin embargo, esta idea es ajena a los teóricos de la abundancia, para quienes el exceso (la abundancia) emerge en virtud de un proceso de desborde de presencia por la presencia,en la medida en que se introduce una "riqueza de sentidos". Y, en tanto Laclau se refiere a la heterogeneidad como un "Real" del sistema, no podemos hablar de exceso de presencia, sino de su (presencia como) ausencia. La heterogeneidad no se articula en términos simbólicos como "abundancia de significados" sino en tanto expresión sintomática de la falta, como demanda; no se revela a través de un desbordamiento de las estructuras, sino como la manifestación de su imposibilidad traumática. En definitiva, la heterogeneidad no remite a un "exceso del discurso" sino a su falla intrínseca, señal del fracaso de la comunidad por constituirse plenamente.

Todos estos aportes buscan conjugarse en una nueva noción de hegemonía, definida como una relación en la cual una particularidad se convierte en el nombre de una universalidad que es inconmensurable con ella (Laclau, 2005). En este sentido, la hegemonía no se constituye ahora como "sutura" o fijación del campo diferencial, sino como la representación de un sitio vacío: la encarnación de lo incondicionado-una plenitud imaginaria- desde el campo condicionado del discurso, a partir del cual una diferencia pasa a ejercer el rol de representar a la totalidad social. La falta constituye así el fundamento del orden hegemónico -el significante vacío en torno al cual se inscriben las diferencias a través de la lógica del objeto a- como así su límite e imposibilidad última, en tanto sobre su dislocación constitutiva emerge un Real reprimido que amenaza con subvertirlo. 
Los desarrollos señalados, en su conjunto, expresan una orientación clara en términos de cómo se comprende el campo de la objetividad a partir de los cambios en la noción de discurso del autor argentino. Si en Hegemonía y estrategia socialista el discurso era abordado como un momento de apertura de lo social -en tanto el juego de la diferencia introduce una suplementación de la realidad, un exceso de discursividad que desborda los sentidos instituidos-, el reconocimiento teórico de la falta conducirá a Laclau a abandonar progresivamente esta idea. Conceptualizada en términos de dislocación de las estructuras, posteriormente la falta se elevará a principio cuasi trascendental de la realidad, en la medida que constituirá una imposibilidad que es necesario representar positivamente. Las nociones de significante vacío primero, y la redefinición del point de capiton posteriormente, irán en esta misma dirección, mientras que la recuperación de la dimensión afectiva posibilitará pensar la falta en su dimensión imaginaria, como un goce mítico pre-simbólico ausente y prohibido que guía las investiduras en el terreno discursivo. Por último, la noción de heterogeneidad añadirá la posibilidad de pensar la dimensión de lo reprimido y su traumático retorno, permitiendo así conceptualizar la irrupción subversiva de la falta al interior del campo simbólico.

\section{Reflexiones finales: el nudo borromeo laclauiano}

Hemos intentado contraponer las perspectivas de Laclau y Žižek en función de sus respectivas conceptualizaciones de la dimensión del discurso como eje de una concepción sobre la objetividad. En función de este contrapunto, hemos intentado reponer algunas de las tensiones que emergen en el intento de Laclau por reponer a lo largo de su obra dos acepciones distintas de esta dimensión: una que sigue los contornos delineados por la mayoría de las variantes del posestructuralismo, que comprende la significación como un juego infinito de sustituciones en el cual cada nueva intervención produce un exceso de sentido que desborda toda estructuralidad; y otra que comprende la significación como representación de la comunidad en tanto objetivación de su propia imposibilidad. Articular infinitud/positividad y finitud/negatividad en una misma definición no es una tarea fácil, lo que llevará al autor a reformular sus categorías en obras sucesivas. El contrapunto entablado con Žižek nos ha permitido, a su vez, ponderar en qué medida la decisión por uno u otro camino implica consecuencias teóricas claramente diferenciadas.

En este sentido, a partir del desarrollo expuesto hemos intentado señalar de qué manera las reformulaciones en el enfoque teórico de Laclau lo han conducido a relegar paulatinamente los conceptos y lógicas sobre los cuales se cimentaba la "abundancia" en su noción de discurso y en relación al terreno de la objetividad (comprendida como campo discursivo). No pretendemos con ello afirmar que la deconstrucción $\mathrm{u}$ otras vertientes del posestructuralismo no lacaniano dejen de ser relevantes para su enfoque. Pero sí consideramos que, en la medida en 
que a partir de las transiciones en su pensamiento el autor abandona progresivamente los vestigios de una ontología de la abundancia, las categorías que refieren a otras tradiciones teóricas quedarán en gran medida subordinadas a una ontología de la falta cuyos contornos serán definidos cada vez con más claridad. Pasaremos ahora abordar algunas discusiones específicas que refieren estas transiciones, que creemos nos permitirán profundizar nuestro punto de vista.

Una de ellas, fundamental en lo que hace a la conceptualización de lo discursivo, refiere al abordaje de lo Real lacaniano en la obra de Laclau, que constituye uno de los puntos que lo ha diferenciado en su debate con Žižek. Laclau no aborda sistemáticamente esta dimensión en su obra, sin embargo las referencias a lo Real abundan en sus publicaciones posteriores a Nuevas reflexiones... Por lo general, Laclau ha tendido a comprender lo Real como un límite puramente negativo que constituye la garantía de la contingencia como condición ontológica trascendental. Es a raíz de ello que Laclau ha trazado un paralelo entre esta noción y la de diferencia, tal cual es abordada por distintos autores del posestructuralismo (y retomada por Marchart para pensar la constitución del pensamiento político posfundacional), para los cuales lo único que siempre retorna a lo largo de la historia no es lo mismo sino, paradójicamente, la diferencia radical (Muñoz González, 2013). En este sentido, al igual que para Marchart, Tønder y Thomassen, el pensamiento de incompletitud estructural así como la contingencia e inestabilidad necesaria de todo fundamento es lo que ha servido como argumento a Laclau para combinar en una misma noción aportes muy distintos basados a la "falta" y la "abundancia".

Sin embargo, en más de una ocasión Laclau ha tendido también a abordar este límite en sus efectos positivos, entendiendo lo Real como un «núcleo traumático resistente a la simbolización, que solo tiene acceso al nivel de la representación al tomar prestados contenidos ónticos, sin ser necesariamente imputable a ninguno de ellos» (2011b, p. 187). Las distintas formas de abordar la falta en su obra posterior a Nuevas reflexiones... avala este camino consistente en pensar lo Real en su inscripción simbólica positiva. Lo cual denota nuevamente una distancia relevante en relación a otros desarrollos del posestructuralismo, en la medida en que -como hemos intentado reconstruir a lo largo de este trabajo- la postulación de que el límite o falta trascendental debe necesariamente ser inscrito al interior del campo simbólico, no constituye un argumento compartido por quienes piensan la realidad a partir de la infinita apertura de lo social. Y lo acerca mucho más a Žižek, para quien, como hemos señalado, lo Real es la inscripción positiva de un vacío o hendidura, la constitución imaginaria de un punto de excepción que sirve de sostén para el orden simbólico. Si el juego de la différance de Derrida es el juego simultáneo de la presencia y la ausencia, para el pensamiento lacaniano, según entiende Žižek, existe un punto en que la presencia y la ausencia configuran una misma y única realidad, en el que el significante encarna su propia imposibilidad y vuelve posible la realidad en tanto metáfora de ella misma -movimiento que el autor esloveno compara con el momento hegeliano de unidad especulativa entre el Ser y la nada, en 
el cual la propia imposibilidad de la Idea deviene condición positiva de nuestra existencia-. ${ }^{23}$

Ahora bien, estos matices en cuanto a la conceptualización de lo Real remiten en gran medida a las distintas formulaciones que ha tenido la falta en el pensamiento de Laclau. Hemos comentado el pasaje que éste realiza en Nuevas reflexiones... del antagonismo a la dislocación como el límite de la objetividad; sin embargo, en dicha obra este límite se sigue comprendiendo como una inadecuación entre el significante y el significado. Cabría interrogarnos por qué esta inadecuación debe ser leída como falta sí, por el contrario, la mayoría de los autores posestructuralistas (aquellos inscriptos en las ontologías de la abundancia) la comprenden en los términos de un desborde de sentido, el momento de una afirmación positiva indeterminada que no se limita a llenar una falta en el significado, sino que redefine al signo mismo. Comprender, en cambio, la inadecuación como falta implica ya asumir que el significante está tachado, marcado por una ausencia constitutiva que refiere a una necesidad de plenitud o completitud estructural, y que el proceso de significación nunca alcanza a llenar. En otras palabras, requiere definir la imposibilidad no como mero límite de los procesos de significación, sino como presencia de una ausencia al interior del orden simbólico.

Como indica un trabajo de Julio Aibar (2014), esto solo es posible si restituimos el registro lacaniano de lo Imaginario, dimensión cuya ausencia explica estas inconsistencias en el pensamiento de Laclau. Para este autor, lo Imaginario constituye un registro integración plena del yo anterior a la castración simbólica, ${ }^{24}$ una dimensión percibida a través de la oposición binaria entre la armonía absoluta y la nada misma, que se constituye a través de la imagen pero no se reduce a ella, y que puede comprenderse en analogía a las propiedades de la Gestalt, a partir de patrones de familiaridad, totalidad, completitud y fijación del sentido. En este sentido, si bien Aibar reconoce que en el pensamiento de Laclau el momento de sutura imposible de la comunidad implica la existencia de una «idea débil de lo Imaginario» (p. 35), plantea que este momento no se justifica: pensar la dislocación como falta, y por ende la equivalencia y la significación totalizante como necesarias, implica conceptualizar este momento de pérdida en su referencia a una previa unidad de sentido, a una imaginaria experiencia pura de armonía y plenitud que brinda coherencia ficcional a la dispersión simbólica.

Podemos también reconocer la importancia de esta dimensión lacaniana retornando a Žižek (2011). Para el esloveno, el error de muchas de las vertientes del posestructuralismo es comprender la realidad solo como una sucesión de sustituciones que se superponen sin sentido. Por el contrario, a partir de Lacan podemos comprender la existencia de la "fantasía" o el "fantasma fundamental" que encubre una cierta brechavacío y sirve como sostén último del ser del sujeto, en la medida en que introduce una ilusión de completitud. La fantasía constituye el núcleo inicial del inconsciente y un apego a la subjetivación constitutiva del sujeto, una escena primordial "masoquista" de rechazo original a través de la cual adquiere el mínimo sostén que necesita su ser. La identificación 
simbólica, en cambio, constituye ya una respuesta simbólica al trauma del "apego apasionado fantasmático". ${ }^{25} \mathrm{La}$ inscripción del significante es entonces correlativa al recubrimiento fantasmático del trauma en el Otro simbólico, un intento -siempre fallido- por conjurar lo Real de nuestra existencia.

Ahora bien, si bien este momento no se haya plenamente conceptualizado, creemos que sí es posible encontrar indicios de él en el pensamiento de Laclau. En primer lugar, la noción de significante vacío introducida en Emancipación y diferencia no instaura únicamente una "fijación" de la realidad: en tanto elemento vector para la constitución de una "universalidad concreta", el significante vacío establece el modo en que es posible pensar la forma vacía de la plenitud dentro de un determinado horizonte histórico. Tenemos aquí una conceptualización semejante a los dos niveles de Žižek (la "fantasía" y la "identificación simbólica"), en la medida en que el marco de coordenadas discursivas proporcionado por el significante vacío ${ }^{26}$ constituye el trasfondo sedimentado de la comunidad como totalidad a lo largo de todo un período histórico, que de este modo instaura patrones de familiaridad, completitud y fijación no problematizados que actúan como sostén imaginario para las identificaciones simbólicas parciales. En este sentido, la relación hegemónica se articula a través de un conjunto de operaciones retóricas metonímicas (las inscripciones simbólicas parciales) que, estableciendo relaciones de equivalencia, se apoyan en un corte metafórico: el nombre del elemento parcial que encarna la comunidad plena (el lugar de la fantasía). Existe en Laclau, entonces, una representación elusiva e imposible que antecede ${ }^{27}$ las diversas inscripciones positivas parciales, y a partir de la cual es posible dotar de una imaginaria unidad de sentido a la dispersión simbólica.

Sin embargo, el abordaje más profundo de la dimensión imaginaria aparece, como hemos esbozado previamente, en La razón populista, a partir de la introducción de la dimensión afectiva. En este punto, a través de la recuperación de la pulsión de muerte freudiana y la lógica del objeto a lacaniano, se postula abiertamente un estado imaginario de armonía y plenitud que guía el investimento de un objeto ordinario como sustituto de la Cosa imposible, de tal modo que éste se erige en el nombre de la totalidad. Este goce mítico y perdido que antecede a la castración, y que en virtud del objeto a se inscribe en el orden simbólico como encarnación de una ausencia irrepresentable -y de este modo instituye el horizonte histórico de la plenitud en una determinada sociedad-, constituye un abordaje del registro Imaginario que no estaba presente en anterior obras (o al menos no se hallaba claramente conceptualizado). Es, volviendo a los términos de Žižek, el “apego apasionado" fantasmático correlativo a la tachadura en el Otro simbólico, que en tanto fuerza afectiva determina las identificaciones en el terreno simbólico -y por ende, los límites de la operación hegemónica-.

Este "giro afectivo" del último Laclau, culmina asimismo con la redefinición de su noción de discurso. La identificación simbólica pasa a comprenderse como investimiento, lo que involucra el establecimiento 
de una catexia diferencial en torno los procesos de significación: la determinación de las sustituciones deja de ser una instancia arbitraria, en la medida en que depende de la lógica del goce. Esto limita el campo de las operaciones discursivas en torno al cual se libra la lucha hegemónica entendido por Laclau como una "guerra de posiciones" por ocupar el lugar vacío de la comunidad-, dado que el juego de las diferencias aparece guiado por algo externo ${ }^{28}$, en tanto existe una "fuerza" que orienta la investidura. Como el propio Laclau (2005) señala, las sustituciones significantes en el terreno discursivo «están dominadas por el inconsciente» (p. 142), de modo tal que la ligazón entre el sujeto (de la falta) y el objeto parcial aparece estructurada por la búsqueda de una jouissence castrada e imposible.

En este sentido, en su obra posterior a Hegemonía y estrategia socialista Laclau concibe progresivamente "lo discursivo" en los términos del registro de lo Simbólico lacaniano, un orden cuya estructuración depende no de la estabilización del significado sino de la encarnación de una falta o pérdida constitutiva en el terreno del significante, a partir de la cual es posible pensar la objetividad en su plenitud imposible (y este ejercicio es lo que justamente define a la hegemonía como lógica política). Ahora bien, como hemos indicado, esta redefinición del discurso es indisociable de una noción de falta como límite de la objetividad que el autor argentino conceptualiza a partir de nociones como dislocación y antagonismo, que se constituyen cada vez más en analogía con lo Real lacaniano. Y, al mismo tiempo, se vincula a una dimensión de lo Imaginario que Laclau aborda a partir de los procesos que hacen posible la encarnación de la universalidad como el momento de plenitud ausente de lo social. Existen entonces, en la obra de nuestro autor, categorías que cumplen la función de los tres registros que se hallan entrelazados en el nudo borromeo lacaniano: lo Real, lo Simbólico y lo Imaginario. Esto nos lleva a refrendar la tesis según la cual el pensamiento del autor argentino, en sus últimas obras, se inscribe de manera clara en el marco de las ontologías de la falta, abandonando las premisas de su enfoque anterior que comprendía una noción de discurso entendida como abundancia.

De modo que antes que cuestionar a Laclau, como en ocasiones lo han hecho los seguidores de Lacan, por su insuficiente conceptualización de las dimensiones del psicoanálisis lacaniano, tal vez podríamos realizar una interrogación en el sentido opuesto: si la subordinación de las categorías laclauianas a un pensamiento basado en la falta no ha eclipsado o neutralizado los efectos introducidos por los elementos no lacanianos de su enfoque, en su búsqueda por armonizar y volver coherentes sus propias premisas teóricas. Hemos buscado esbozar una respuesta a esta pregunta a partir de la contraposición entre las nociones de falta y abundancia en tanto principios ontológicos, pero es posible indagar el modo en que este viraje hacia la falta nos interroga sobre otras dimensiones del pensamiento del autor argentino. Comprender, por ejemplo, la falta en relación a su inscripción de un goce imposible como proceso articulado por el inconsciente conlleva, como ha señalado Stravrakakis (2010), el riesgo de rozar el esencialismo, ya que esta investidura no se agota en el 
terreno del discurso sino que está estructurada en torno a un núcleo Real, que implica un goce que incluso se traduce en los cuerpos. Al mismo tiempo, asumir estas suposiciones probablemente nos conduzca alimitar el espacio de contingencia asignado a las luchas en el terreno discursivo por alcanzar la hegemonía, poniendo seriamente en cuestión la primacía ontológica de lo político en el pensamiento del autor argentino.

Por razones de espacio no podemos abordar estos debates en su complejidad. Es posible decir, sin embargo, que es en la conceptualización de lo político donde se verán las diferencias más importantes entre el pensamiento de Laclau y la propuesta teórica de Žižek, que en gran medida llevarán a su ruptura posterior. El camino desarrollado hasta aquí nos ha permitido indagar de qué modo la construcción de las premisas ontológicas de ambos autores plantea similitudes considerables en su pensamiento, que no pueden ser opacadas amén de sus enfrentamientos teórico-políticos. Estas similitudes residen, principalmente, en su esfuerzo común por hacer de la falta lacaniana el fundamento de sus respectivos enfoques ontológicos.

\section{Referencias}

Aibar, J. (2014). La falta en Laclau: lo imaginario. Identidades, (6), año 4, 23-37. Antonelli Marangi, M. S. (2014). Aportes sobre la relación de Deleuze con Lacan. Verba Volant. Revista de Filosofía y Psicoanálisis, (1), año 4. https:// publicacionescientificas.uces.edu.ar/index.php/FiliyPsi/article/view/74

Butler, J.; Laclau, E. y Žižek, S. (2011). Contingencia, hegemonia, universalidad. Diálogos contemporáneos de la izquierda. Buenos Aires: FCE.

Critchley, S. y Marchart, O. (Coord.) (2008). Laclau. Aproximaciones criticas a su obra. Buenos Aires: FCE.

Deleuze, G. y Guattari, G. (1985). El Anti Edipo. Capitalismo y esquizofrenia. Barcelona: Paidós.

Derrida, J. (1989). La estructura, el signo y el juego en el discurso de las ciencias humanas. En Derrida, J. La escritura y la diferencia (pp. 383-401). Barcelona: Anthropos.

Derrida, J. (2017). De la gramatología. Buenos Aires: Frente a la Hogera.

Tønder, L. y Thomassen, L. (Coord.) (2005) Radical Democracy: Politics Between Abundance and Lack (Reappraising the Political). Manchester: Manchester University Press.

Laclau, E. (1996). Emancipación y Diferencia. Buenos Aires: Ariel.

Laclau, E. (2000a) Nuevas Reflexiones sobre la revolución de nuestro tiempo. Buenos Aires: Nueva Visión.

Laclau, E. (2000b). La imposibilidad de la sociedad. En Laclau, E. Nuevas Reflexiones sobre la revolución de nuestro tiempo (pp. 103-107). Buenos Aires: Nueva Visión.

Laclau, E. (2005). La razón populista. Buenos Aires: FCE.

Laclau, E. (2008). Atisbando el futuro. En Critchley, S. y Marchart, O. (Coord.) Laclau. Aproximaciones criticas a su obra (pp. 347-404). FCE: Buenos Aires. 
Laclau, E. (2011a). Identidad y hegemonía: el rol de la universalidad en la construcción de lógicas políticas. En Butler, J., Laclau, E. y Žižek, S. (Coord.) Contingencia, hegemonia, universalidad. Diálogos contemporáneos de la izquierda (pp. 51-95). Buenos Aires: FCE.

Laclau, E. (2011b). Estructura, historia y lo político. En Butler, J., Laclau, E. y Žižek, S. (Coord.). Contingencia, hegemonia, universalidad. Diálogos contemporáneos de la izquierda (pp. 185-215). Buenos Aires: FCE.

Laclau, E. (2013). Argentina: anotaciones preliminares sobre los umbrales de la política. Debates y Combates, (5), año 3, 9-18.

Laclau, E. y Mouffe, C. (2004). Hegemonía y estrategia socialista. Hacia una radicalización de la democracia. Buenos Aires: FCE.

Marchart, O. (2005). The abscence at the heart of presence: radical democracy and the 'ontology of lack'. En Tønder, L. y Thomassen, L. (Coord.) Radical Democracy: Politics Between Abundance and Lack (Reappraising the Political) (pp. 17-32). Manchester: Manchester University Press.

Marchart, O. (2009). El pensamiento politico posfundacional. La diferencia politica en Nancy, Badiou, Lefort y Laclau. Buenos Aires: FCE.

Muñoz González, D. M. (2013). Nietzsche y los filósofos de la diferencia. Franciscanum, vol. IV (159), 17-56.https://www.redalyc.org/ pdf/3435/343529080002.pdf

Norval, A. (2005). Theorising hegemony: between deconstruction and psychoanalysis.En Tønder, L. y Thomassen, L. (Coord.) Radical Democracy: Politics Between Abundance and Lack (Reappraising the Political) (pp. 86-103). Manchester: Manchester University Press.

Retamozo, M. (2011). Tras las huellas de Hegemón. Usos de hegemonía en la teoría política de Ernesto Laclau. Utopia y Praxis Latinoamericana, vol. 16 (55), Universidad del Zulia, Venezuela, 39-57.

Stravakakis, Y. (2010). La izquierda lacaniana. Psicoanálisis, teoria, politica. Buenos Aires: FCE.

Thomassen, L. (2005). In/exclusions: towards a radical democratic approach to exclusion.En Tønder, L. y Thomassen, L. (Coord.) Radical Democracy: Politics Between Abundance and Lack (Reappraising the Political) (pp. 103-119). Manchester: Manchester University Press.

Widder, N. (2005). Two routes from Hegel. En Tønder, L. y Thomassen, L. (Coord.) Radical Democracy: Politics Between Abundance and Lack (Reappraising the Political) (pp. 32-50). Manchester: Manchester University Press.

Žižek, S. (2000). Más allá del análisis del discurso. En Arditi, Benjamin (Coord.) El reverso de la diferencia. Identidad y politica (pp. 169-179). Caracas: Nueva Sociedad.

Žižek, S. (2003). El espectro de la ideología. En Žižek, S. (Coord.). Ideología. Un mapa de la cuestión (pp. 7-43). Buenos Aires: FCE.

Žižek, S. (2011) El espinoso sujeto. El centro ausente de la ontología política. Buenos Aires: Paidós.

Žižek, S. (2012) El sublime objeto de la ideología. Buenos Aires: Siglo XXI.

Žižek, S. (2016). El resto indivisible. Buenos Aires: Ediciones Godot. 


\section{Notas}

1. Cabe aclarar que el pensamiento de Žižek también ha variado a lo largo de sus obras, y la influencia de Laclau ha sido también importante para su enfoque (sobre todo en sus primeros trabajos orientados al análisis de la ideología). Su distanciamiento posterior del autor argentino -y su acercamiento al pensamiento de Alain Badiou- quedará evidenciado en sus fuertes contrapuntos y polémicas posteriores. Sin embargo, más allá de estos cambios, la perspectiva teórica del autor esloveno buscará siempre situarse sin ambages bajo el paradigma lacaniano, privilegiando la postulación de la falta como fundamento inequívoco de su enfoque.

2. Sobre todo en las interpretaciones que toman como eje central para la comparación entre ambos autores los respectivos proyectos políticos que ellos proponen. En este sentido, la inscripción de ambos al interior de la "izquierda lacaniana" en la obra de Stavrakakis (2010) ha llevado a que muchos distingan entre distintas variantes políticas al interior de ese campo: una "reformista" (expresada por Laclau) y otra "revolucionaria" (encarnada por Žižek y Badiou).

3. La discusión teórica sobre esta distinción es abordada en la primera parte de este volumen -"Radical democracy: abundance and/or lack?"-, que es donde concentraremos nuestra atención. Los trabajos que conforman la segunda parte de la obra - "The politics of radical democracy" se orientan específicamente a la discusión sobre las distintas dimensiones del proyecto de la democracia radical.

4. Traducción del autor del artículo. Fragmento original: «which does not appreciate the complexity and depth of social life, but instead reduces the experience of difference to a question of failure».

5. La cuestión de la diferencia ha sido uno de los principales problemas filosóficos abordados por el posestructuralismo, especialmente en las obras de autores como Deleuze, Derrida, Foucault y Lyotard. Como indica un trabajo de Muñoz González (2013), la “diferencia radical” cobrará sentido específico en cada de uno estos autores, sin embargo su rasgo común será su rechazo absoluto a toda pretensión de reducir la identidad a una unidad o principio absoluto, afirmando en cambio la multiplicidad y diferencialidad de toda identidad, y la comprensión del ser en su devenir.

6. Traducción del autor del artículo. Fragmento original: «'l] ack refers to a positivity of desire and not desire to a positivity of lack'. Here, the phenomenon of positivity or superabundance of being is claimed to be ontological prior to the phenomenon of lack and negativity».

7. Si bien en nuestro trabajo, siguiendo la distinción trazada por Tønder y Thomassen (2005), enmarcaremos a Derrida en las "ontologías de la abundancia”, cabe aclarar que el trabajo de Marchart postula que Derrida configura una "tercera opción": la ontología de la diferencia (Marchart, 2005).

8. Para el rastreo de las influencias teóricas de los pensadores de la abundancia nos hemos basado en particular en un notable artículo de Muñoz González (2013).

9. Sin bien la crítica a Husserl y -en especial- a Hegel, es un rasgo común y determinante para estos filósofos, la crítica a Heidegger varía de un autor a otro, cuya influencia ha sido importante en particular para el trabajo de Derrida.

10. Una de las discusiones planteadas por los autores es la oposición entre aquella postura que acuerda con las intuiciones fundamentales de Spinoza sobre la "unicidad de la naturaleza", afirmando que no existe nada por fuera del campo del ser -la postulación de una inmanencia pura, cuyo exponente principal es Deleuze-, y otra que continúa la tradición de la “teología negativa”, sosteniendo que el campo del ser nunca es suficiente por sí mismo -una posición en la que es posible encuadrar a toda posición trascendental o cuasi 
trascendental, desde Lacan hasta (determinadas lecturas de) Derrida- (Tønder y Thomasen, 2005).

11. La excepción vale para el trabajo de Nathan Widder (2005), quien tomando claro partido por la ontología deleuziana, cuestiona a los teóricos de la falta su subordinación de la identidad a la negatividad de la diferencia.

12. Esta idea de fundamentos ontológicos inestables es lo que le permite a Marchart sostener la existencia de una nueva corriente teórica que se constituye sobre la base y en los márgenes del pensamiento posestructuralista: el pensamiento político posfundacional. Esta idea aparece especialmente desarrollada en su ya clásica obra "El pensamiento político posfundacional" (2009).

13. Nos referimos, por supuesto, al pensamiento de Deleuze a partir de su obra en coautoría con Felix Guattari, el Anti Edipo (1985). Existe un Deleuze anterior más cercano al estructuralismo y al pensamiento de Lacan; para una periodización del pensamiento de Deleuze y su relación con Lacan, ver Antonelli Marangi (2014).

14. Como indica Norval (2005), la apropiación laclauiana de Derrida está permeada por la lectura de Rodolphe Gasché (en su obra The tain of the mirror), quien al conceptualizar las "infraestructuras de la deconstrucción" nos presenta un Derrida "cuasi trascendental".

15. El concepto de "puntos nodales" constituye una reapropiación de la noción lacaniana de point de capiton. Esta noción, sin embargo, adquirirá un sentido distinto en el pensamiento de Laclau, amoldada a las premisas más cercanas a la deconstrucción. Como veremos más adelante, recién en La razón populista (2005) el autor buscará retomar el sentido original de la conceptualización lacaniana.

16. Nos referimos al "segundo Wittgenstein", el de Investigaciones filosóficas, que ha tenido una importante influencia en la obra de Laclau.

17. Martín Retamozo (2011) conceptualiza la hegemonía como "una categoría y tres conceptos": una lógica política de institución de las identidades colectivas, una lógica de constitución del orden en su dimensión global y una lógica a partir del cual es posible pensar constitución de la objetividad como tal.

18. La discusión sobre la noción de hegemonía es amplia y no podemos abordar sus distintas dimensiones en este trabajo, por lo cual nos limitamos a reconstruir sintéticamente algunos de sus principales elementos. Una obra que resume algunas de las principales discusiones contemporáneas sobre esta noción es Laclau. Aproximaciones criticas a su obra, de Critchley, Simon y Marchart, Oliver (2008).

19. En la reconstrucción de los razonamientos del autor esloveno nos basamos fundamentalmente en Žižek, 2003, 2011, 2012 y 2016.

20 «El logro de Hegemonía... se cristaliza en el concepto de «antagonismo social»: lejos de reducir toda realidad a una suerte de juego de lenguaje, el campo socio-simbólico es concebido como estructurado en torno de una cierta traumática imposibilidad, en torno de una fisura que no puede ser simbolizada» (Žižek, 2000, p. 169).

21. Interrogado por David Howarth sobre la relación entre el "punto nodal" y el "significante vacío", Laclau responde: «Tienen exactamente el mismo referente y la distinción radica en que el "punto nodal" hace alusión a la función articulatoria, mientras que su carácter vacío apunta hacia su significación universal» (Laclau, 2008, p. 397).

22. Como indica Norval (2005), la conceptualización del objeto parcial marca un diferendo entre Laclau y Žižek: mientras que para este último constituye un mero señuelo cuya naturaleza positiva es irrelevante, para Laclau la definición del objeto a como "significante de la plenitud" es expresión de una lucha hegemónica, cuyo resultado dependerá del contexto político sobre el que se opera.

23. El espacio limitado nos impide extender este debate, pero la conceptualización de lo Real ha constituido uno de los puntos de discusión más importantes 
abordados por Butler, Laclau y Žižeken su obra conjuntaContingencia, hegemonia y universalidad (2011).

24. Aun cuando, para el autor, este registro no trascurre al margen de toda intervención simbólica, como lo refleja el lugar ocupado por la madre en el estadio del espejo (Aibar, 2014).

25. El concepto de "apegos apasionados" proviene de Judith Butler, de quien Žižek lo toma y re-conceptualiza en los términos de su propia propuesta teórica.

26. Antes de desarrollar su noción de significante vacío, en su obra Nuevas reflexiones... (2000) Laclau anticipó reflexiones en la misma dirección de este concepto, a partir de su referencia a los «significantes imaginarios que constituyen el horizonte de una comunidad» (p. 81, el destacado es nuestro), vinculando así en una temprana instancia la representación imposible de la comunidad con el registro de lo Imaginario.

27 "Antecede" en el sentido de que, más allá de que toda hegemonía es cambiante y sus fronteras pueden sufrir desplazamientos -es por ello para Laclau los significantes vacíos son, en esencia, flotantes-, toda interpelación simbólica particular se realiza en el marco de una sociedad constituida históricamente a través de procesos hegemónicos, y por ende actúa en el marco de determinadas coordenadas que a su vez delimitan "umbrales" para la acción política (Laclau, 2013). En la constitución de esa hegemonía, sin embargo, Laclau (2005) subraya que no hay un "antes" ni un "después": ésta existe en la medida en que diversos elementos parciales -las demandas- se unifican en su equivalencia, pero a su vez, la "cadena de equivalencias" designa a los elementos articulados al inscribirlos en nueva formación discursiva. Por razones de espacio no podemos abordar estos debates en su especificidad.

28. "Externo" no en el sentido de ser exterior al discurso (de hecho, Laclau declama repetidamente que la significación y el afecto son indisociables), sino en función del hecho de que el "juego de las diferencias" no agota los fundamentos (precarios) del ser: es preciso remitirse a un afecto inconsciente que anima estas diversas sustituciones. En los términos de Žižek, es necesario apuntar «más allá de la interpelación”, lo cual "no tiene nada que ver con una especie de irreductible dispersión y pluralidad del proceso significante”, sino con una dimensión que refiere al "cuadrado del deseo, la fantasía, la falta en el Otro y la pulsión pulsando en torno a algún insoportable plusgoce» (2012, p. 170). 